\title{
The Effectiveness of Amniotic Membrane as Skin Graft Fixator and Graft Take Accelerator, a Clinical Research Study
}

\author{
Ari Raheem Qader', Dana A Abdilkarim ${ }^{2 *}$, Abdulsalaam M. Yonis ${ }^{3,4}$ \\ ${ }^{1}$ Department of Surgery, University of Sulaimani, Sulaimani, Kurdistan Region, Iraq. \\ ${ }^{2}$ Department of Community Health, Sulaimani Polytechnic University, Sulaimani, Kurdistan Region, Iraq. \\ ${ }^{3}$ Department of Health, General Directorate of Health, Mosul, Iraq. \\ ${ }^{4}$ Sulaimani Burn and Plastic Surgery Hospital, Sulaimani, Kurdistan Region, Iraq.
}

*Corresponding Author: dana.abdilkarim@spu.edu.iq

Received | December 18, 2015

Accepted | January 21, 2016

\section{Abstract}

The amnion is a thin semi-transparent tissue forming the innermost layer of the fetal membrane. It has been claimed to be one of the most effective biological skin substitutes used in burn wounds, with efficiency of maintaining low bacteria count.

This study was set to evaluate the effectiveness of amniotic membrane as skin graft fixator and graft take accelerator.

This work is a prospective study carried out in Burns and Plastic Surgery Hospital in Sulaimani for period from $1^{\text {st }}$ of April to end of August 2015 on convenient sample of 33 burned patients.

Mean age of burned patients was $24 \pm 19$ years, Most $(\mathbf{9 3 . 9 \%})$ of burned patients were treated by covering raw area with meshed SSG and only two patients were treated by covering with sheet SSG. Most (90.9\%) of burned patients who had treated with covered SSG had taken in comparison with non-covered SSG with amniotic membrane. Postoperative complications for skin areas treated with covered technique were 3; graft loss due to infection, graft loss due to shearing and graft loss due to hematoma.

Amniotic membrane induces the graft take among burned skin and fastening the skin healing with fewer complications.

Key words: Amniotic membrane, Biologic Dressing, Split Skin Graft (SSG), Graft take.

\section{Introduction}

Amnion

The amnion is a thin semi-transparent tissue forming the innermost layer of the fetal membrane. As fresh amnion carries risk of contaminations and disease transmission, amnion is collected from placentae of selected and screened donors. Various preservation methods have been introduced, including cryopreservation in liquid nitrogen, preservation in silver nitrate, storage in antibiotics solution, glycerol-preserved sheets, dried sheets and gamma-irradiated sheets (Halim et al, 2010). It has been claimed to be 
one of the most effective biological skin substitutes used in burn wounds, with efficiency of maintaining low bacteria count. It also has advantages of reducing loss of protein, electrolytes and fluids, decreasing the risk infection, minimizing pain, acceleration of wound healing and good handling properties (Bujang et al., 2010).

Several methods of graft fixation have been described (Sangwan et al., 2007, Rudge, 2007). A common technique is to use stitches but this is time consuming and the stitches need to be removed after graft take. Placing surgical drapes over the graft is another method but these must be removed on the second or third day when the grafts are still not well vascularized, and this can lead to graft failure. Fixation with skin staples was introduced as a fast and reliable method for graft fixation (Alexander et al., 2005) however it is expensive and stressful for the patient as these staples must be removed which can be painful and frightening, particularly for children. Forgotten staples are another troublesome complication (Mohammadi et al., 2009).

Another technique uses steri-strip micro porous tapes for fixation, but the surrounding skin must be completely healthy to retain the tapes (Rudge, 2007). Other methods applying different materials such as honey (Ilteris Murat, 2007) or cyanoacrylate (Adler et al., 2007) have been designed.

We would like to present a method of graft fixation pioneered at our burn center and found convenient for both patient and surgeon, using amniotic membrane as fixator. Several studies have shown that the application of amniotic membrane as a biological dressing in the management of burns is accompanied by rapid reepithelialization and healing (Mohammadi and Ghoddusi, 2008, Mohammadi and Ghoddusi, 2010, Antasov et al., 1994).

\section{Patients and Methods}

\section{Patients}

A prospective study carried out in Burns and Plastic Surgery Hospital in Sulaimani to evaluate the effectiveness of amniotic membrane as skin graft fixator and take accelerator in a period from $1^{\text {st }}$ of April to end of August 2015 on convenient sample of 33 burned patients was selected from patients presented to Burns and Plastic Surgery Hospital in Sulaimani.

The patients were evaluated preoperatively by taking history, clinical examination and laboratory investigations. Fresh amniotic membrane was obtained from Caesarean section patients, seronegative of hepatitis and venereal diseases, no jaundice history, no history of malaria and toxemias. The amniotic membrane was stripped from the placenta and all blood, mucus and debris was removed using $4 \times 4$ moist gauze pieces. The membrane was cut into pieces of $10 \times 10 \mathrm{~cm}$ and spread over sterile piece of surgical gauze (Singh and Chacharkar, 2011).

\section{Surgical technics}

After covering the raw area with SSG half of the grafts is covered and fixed with amniotic membrane and another half fixed by staples and covered with gauze impregnated with oil based ointment. This is followed by the placement of a thick layer of fluff gauze that is then covered with 
an elastic bandage. Dressings were checked daily soakage, discharge and foul smell. Subsequently the dressings were opened in day 4 . The state of graft take was checked for two areas.

\section{Results}

A total of 33 burned patients were treated surgically by covering the raw area with Split Skin Graft (SSG). Mean age of burned patients was $24 \pm 19$ years, $54.6 \%$ of them were $\leq 20$ years old.

About two thirds (69.7\%) of burned patients had flame burn and $30.3 \%$ of them had the scald burn. Most (93.9\%) of burned patients were treated by covering the raw area with meshed SSG and only two patients were treated by covering with sheet SSG (Table 1). Most of burned patients (90.9\%) who had treated surgically by covering SSG with amniotic membrane had taken in comparison with non-covered SSG, (Table 2).

Postoperative complications for areas treated with non-covered technique were 6 complications (3 graft loss due to infection, 2 due to shearing and 1 due to hematoma), while postoperative complications for areas treated with covered technique were 3 ( 1 graft loss due to infection, 1 due to shearing and 1 due to hematoma) (Table 3 ).

Table 1: Surgical operation characteristics.

\begin{tabular}{|l|c|c|}
\hline \multicolumn{1}{|c|}{ Variable } & No. & $\%$ \\
\hline Surgical technique & 31 & 93.9 \\
\hline Meshed split skin graft & 2 & 6.1 \\
\hline Sheet split skin graft & 33 & 100.0 \\
\hline Total & & \\
\hline
\end{tabular}

Table 2: Graft take for covered SSG with amniotic membrane in comparison with non-covered technique.

\begin{tabular}{|c|c|c|c|c|c|c|}
\hline \multirow{2}{*}{ Variable } & \multicolumn{2}{|c|}{ Non-covered } & \multicolumn{2}{|c|}{ Covered } & \multirow{2}{*}{$\chi^{2}$} & \multirow{2}{*}{$\mathbf{P}$} \\
\hline & No. & $\%$ & No. & $\%$ & & \\
\hline \multicolumn{5}{|c|}{ Graft Take } & \multirow[t]{4}{*}{0.5} & \multirow[t]{4}{*}{0.2} \\
\hline Yes & 27 & 81.8 & 30 & 90.9 & & \\
\hline No & 6 & 18.2 & 3 & 9.1 & & \\
\hline Total & 33 & 100.0 & 33 & 100.0 & & \\
\hline
\end{tabular}


Table 3: Distribution of postoperative complications according to covered SSG with amniotic membrane in comparison to non-covered technique.

\begin{tabular}{|c|c|c|c|c|c|c|}
\hline \multirow{2}{*}{ Variable } & \multicolumn{2}{|c|}{ Non-covered } & \multicolumn{2}{|c|}{ Covered } & \multirow[t]{2}{*}{$\chi^{2}$} & \multirow[t]{2}{*}{$\mathbf{P}$} \\
\hline & No. & $\%$ & No. & $\%$ & & \\
\hline \multicolumn{5}{|l|}{ Postoperative complications } & $0.3^{*}$ & 0.8 \\
\hline Graft loss due to infection & 3 & 50.0 & 1 & 33.3 & & \\
\hline Graft loss due to shearing & 2 & 33.3 & 1 & 33.3 & & \\
\hline Graft loss due to hematoma collection & 1 & 16.7 & 1 & 33.3 & & \\
\hline Total complications & 6 & 100.0 & 3 & 100.0 & & \\
\hline
\end{tabular}

\section{Discussion}

Indications of amniotic membrane usage continue to expand and encompass varying range of procedures. There are three representative forms of amniotic membrane available; fresh, cryopreserved and dried amniotic membrane. Studies seem to indicate that freeze dried-air preserved amniotic membranes show no qualitative changes in growth factor and cell contents even after 5 years of storage as compared to the other two types (Kesting et al., 2010, Singh and Chacharkar, 2011).

In any form, the membrane is easy to handle as a dressing material and adheres well to the bare connective and osseous tissue (Chopra and Thomas, 2013, Kim et al., 2009).

In the present study, covered skin graft with amniotic membrane had a graft take in $90.9 \%$ compared to 81.8 areas had taken by using non covering technique. This finding is consistent to results of Ganatra, et al. study in Pakistan (Ganatra and Bhura, 2004) which was observational study on 30 burned cases treated surgically with SSG with two areas, one covered with amniotic membrane and the other was not covered and concluded that amniotic membrane was decreasing healing time.

Amniotic membrane immediately adheres to the grafted areas and fixes skin graft to their bed, which eliminates suturing on extremities and diminishes the need for suturing on other body parts. It also eliminates painful suture removal, accelerates graft take and decreases traumatic graft loss induced by suture removal. The revascularization of a skin graft depends on immobilization of the graft on the wound bed. In cases where circular dressings are needed, the graft may be displaced under the dressing, leading to partial graft loss (Rudge, 2007).

Current study revealed that covered areas with amniotic membrane had less complication than non-covered areas. This finding agreed with results of Kumar A, et al study in India (Kumar et al., 2015) which found that amniotic membrane has the potential to function as a barrier for infection and the unique properties associated with 
this material can augment its potential as a matrix for tissue regeneration. The current consensus is that the intimate adherent property of the biological dressing to an open wound in some way suppresses bacterial proliferation and helps to eliminate existing bacteria (Gonce et al, 1990).

A number of factors may contribute to this effect. In a clean surgical wound, the collagen of the graft or biological dressing, via its hemostatic properties, will help to stop bleeding and thus prevent subsequent hematomas, which would provide opportunities for bacterial proliferation. In addition, the very close bonding between graft and wound eliminates dead space in which serous exudates could collect and encourage bacterial growth (Kearney, 1996).

When wounds are contaminated, grafts or biological dressings can not only suppress bacterial growth but also reduce the existing microbial population density. A likely explanation for this phenomenon is the bonding of the graft to the wound bed by fibrin: the bacteria are trapped in the thin fibrin matrix linking the collagen fibers of the graft with the collagen of the wound bed. The fibrin matrix provides an ideal substratum for migration of phagocytes and ensures that all the bacteria are within reach of the phagocytes (Kearney, 1996).

Amniotic membrane has been found an effective biological dressing for burns, as it diminishes the oozing of plasma, bacterial count, and fluid, protein and heat loss (Mohammadi and Ghoddusi Johari, 2008; Mohammadi and Ghoddusi, 2010, Antasov et al., 1994).

\section{Conclusions}

Amniotic membrane induces the graft take among burned skin and fastening the skin healing. Split skin graft covered with amniotic membrane is associated with fewer complications.

\section{References}

Halim AS, Khoo TL, Mohd. Yussof SJ (2010). Biologic and synthetic skin substitutes: An overview. Indian Journal of Plastic Surgery. 43(1):S23-S28.

Bujang-Safawi E, Halim AS, Khoo TL, Dorai AA (2010). Dried irradiated human amniotic membrane as a biological dressing for facial burns: A 7-year case series. Burns. 36:876-82.

Sangwan VS, Burman S, Tejwani S, Mahesh SP, Murthy R (2007). Amniotic membrane transplantation: a review of current indications in the management of ophthalmic disorders. Indian $\mathbf{J}$ Ophthalmol. 55(4):251-60.

Rudge R (2007). An easy and safe method of splitthickness skin graft fixation. Burns. 33:1074-5.

Alexander G, Al-Rasheed AA (2005). Skin stapler removal by artery forceps: a hazardous practice? Burns. 31:116.

Mohammadi AA, Ghoddusi johari H (2009). Forgotten staples. Burns.35: 611.

Ilteris Murat E (2007). A different and safe method of split thickness skin graft fixation: medical honey application. Burns. 33:782-7.

Adler N, Nachumovsky S, Meshulam-Derazon S, AdEl D (2007). Skin graft fixation with cyanoacrylate tissue adhesive in burn patients. Burns. 33:803.

Mohammadi AA, Ghoddusi Johari H (2008). Amniotic membrane: A skin graft fixator convenient for both patient and surgeon. Burns. 34:1051-1052.

Mohammadi AA, Ghoddusi Johari H (2010). Anchoring sutures: useful adjuncts for amniotic membrane for skin graft fixation in extensive burns and near the joints. Burns. 36:1134-1141.

Antasov W, Mazalova J, Todorod R, Stereva K, Trencheva W (1994). Use of amniotic membrane as biological dressing in contemporary treatment of burn. Ann Medit Burns Club. 7:202-5.

Kesting MR, Loeffelbein DJ, Classen M, SlottaHuspenina J, Hasler RJ, Jacobsen F, et al (2010). Repair of oronasal fi stulas with human amniotic membrane in minipigs. Br J Oral Maxillofac Surg. 48:131-5. 
Singh R, Chacharkar MP (2011). Dried gammairradiated amniotic membrane as dressing in burn wound care. J Tissue Viability. 20:49-54.

Chopra A, Thomas BS (2013). Amniotic membrane, A Novel Material for Regeneration and Repair. J Biomim Biomater Tissue Eng. 18:1-8.

Kim SS, Song CK, Shon SK, Lee KY, Kim CH, Lee MJ, et al (2009). Effects of human amniotic membrane grafts combined with marrow mesenchymal stem cells on healing of fullthickness skin defects in rabbits. Cell Tissue Res. 336:59-66.

Ganatra MA, Bhura S (2004). Management of skin graft donor site by irradiated amniotic membrane. Pakistan Journal of Surgery. 19 (2): 82-85.

Kumar A, Chandra V, Reddy AA, Reddy BH, Reddy C, Naveen A (2015). Evaluation of clinical, antiinflammatory and anti-infective properties of amniotic membrane used for guided tissue regeneration: A randomized controlled trial. Surgical Research Journal. 12 (2): 127-135.

Gonce S, Miskell P, Waymack JP (1990). A comparison of biobrane vs homograft for coverage of contaminated burn wounds. Burns. 14: 409-412.

Kearney J (1996). Banking of skin grafts and biological dressing. In: "Principle and practice of burns management", John A.D. Settle (ed.), Churchill Livingstone, New York, 329-51. 